\title{
Hacer trabajo de campo en lo efímero. Etnografia feminista en la movilidad
}

\author{
Do fieldwork ephemerally. Feminist ethnography in mobility
}

Mónica Patricia Toledo González*

\section{Resumen}

Este texto presenta una reflexión feminista sobre el trabajo de campo realizado con población migrante que transita por México en condiciones de irregularidad migratoria. Se analizan las vivencias de las etnógrafas que realizaron trabajo de campo para el estudio de flujos migratorios, en un contexto prevalecientemente masculino. También se reflexionan las impresiones de un estudio entendido desde el ser mujer.

Palabras claves. Etnografía feminista, movilidad, migración hondureña.

\begin{abstract}
This text presents a feminist reflection on the field work carried out with the migrant population that transits through Mexico in conditions of migratory irregularity. The experiences of the ethnographers who carried out the field work for the study of migratory flows are analyzed, in a predominantly male context. The impressions of a study understood from being a woman are also reflected.
\end{abstract}

Keywords. Feminist ethnography, mobility, Honduran migration.

Fecha de recepción: Abril 2021

Fecha de aprobación: Diciembre 2021

\section{Introducción}

Esta participación presenta una reflexión feminista sobre el trabajo de campo realizado en el marco del proyecto "Tránsitos Precarios, Migrantes Centroamericanos y su Trayecto por el Altiplano Central Mexicano"1. En dicho proyecto se adoptó una

\footnotetext{
* Doctora en Antropología por el Centro de Investigaciones y Estudios Superiores en Antropología Social, sede CDMX, México. Profesora de Tiempo Completo en la Facultad de Ciencias para el Desarrollo Humano, Universidad Autónoma de Tlaxcala, México.
} 
metodología cualitativa, fundamentalmente proveniente de la etnografía. El trabajo de campo se inició como voluntarias en el albergue La Sagrada Familia desde 2016 hasta marzo de 2019. El grupo de investigación ha estado conformado mayoritariamente por mujeres que acudimos de manera intermitente a este albergue ubicado en la ciudad de Apizaco, en el estado de Tlaxcala ubicado en el centro de México.

Este albergue es una institución que brinda soporte humanitario, pues otorga servicios a la población migrante como alimentación, descanso, atención médica, servicio telefónico, ropa, artículos de higiene personal y orientación legal. Recibe principalmente a migrantes centroamericanos que circulan por México en condiciones irregulares, es decir, que no cuentan con los permisos necesarios para ingresar al país $y$, que en su mayoría, tienen como destino Estados Unidos o la frontera norte de México.

Harding (2002) nos invita a desarrollar tres elementos epistemológicos concatenados para desarrollar una metodología feminista -que no solamente se restrinja a sumar o agregar a mujeres a las investigaciones-; estos elementos son: investigar sobre las experiencias de las mujeres -en plural-, pues la experiencia de ser mujer varía de acuerdo a las categorías culturales de los contextos específicos; estar a favor de las mujeres, y situar a la investigación en el mismo plano critico que el objeto explícito de estudio. Es en este sentido que el texto busca aportar al desarrollo de la epistemología feminista, desde una etnografía feminista: situada y reflexiva.

Este artículo se compone de cinco secciones. En la primera "De los tránsitos precarios por el Altiplano Central Mexicano" se apuntan las líneas teóricas desarrolladas en la investigación realizada en el marco del proyecto. La segunda "De la etnografía clásica a la etnografía feminista" explora los fundamentos epistemológicos de esta reflexión. La tercera sección "La Sagrada Familia como el espacio de investigación" presenta las características de esta institución que brinda soporte humanitario. La cuarta sección "Etnografiar a las etnográfas", muestra las implicaciones de hacer trabajo de campo siendo mujeres; la última sección "Lo efímero en campo", explora la relación entre este método de investigación y el tiempo en el contexto de la movilidad irregular. Finalmente se ofrecen las conclusiones.

\section{De los tránsitos precarios por el Altiplano Central Mexicano}

El estado de México ejecuta políticas migratorias de restricción y contención regularmente violenta y sistemática- de las personas que buscan circular de forma temporal por territorio mexicano. En este caso, me refiero a personas de origen centroamericano que buscan llegar a la frontera norte para ingresar a Estados Unidos. Los orígenes de estos tránsitos, retomando a Durand son la violencia sistemática, la pobreza neoliberal y la impunidad institucional (Durand, 2020). La posición geográfica de México representa un espacio estratégico y conflictivo: la frontera norte conecta con uno de los países más poderosos del mundo, y al sur, colinda con la región de Centroamérica, caracterizada por la pobreza, la violencia y la desigualdad. Esta

1 Problemas Nacionales 5687 financiado por el FOINS del Consejo Nacional de Ciencia y Tecnología, México. 
posición ha generado una multiplicidad de restricciones, que se objetivan en múltiples leyes, programas y planes, tanto del gobierno estadounidense, como del mexicano, con la finalidad de controlar los flujos que circulan del sur hacia el norte. En nuestro país se materializan las políticas de control migratorio y vigilancia fronteriza de Estados Unidos, y frente al cual funge como un estado de contención (Guirudon y Joppke, 2001 en París, 2016).

En esta investigación se utilizó el paradigma de las movilidades y la perspectiva de los territorios de espera. El estudio de los tránsitos migratorios se ha abordado desde el paradigma de movilidad; pues de acuerdo con Sheller y Urry (2018) además de colocar en el centro del análisis el movimiento, lo vincula con instituciones, prácticas y relaciones sociales; integra la diversidad de modalidades (diferentes modos y combinaciones del movimiento) ${ }^{2}$; implica el uso de modelos específicos de investigación que permitan dar cuenta de esta diversidad; enfatiza el reconocimiento de las combinaciones de movimientos y anclajes dentro de las diversas formas de movilidad. Dicho paradigma reconoce cómo algunas prácticas sociales pueden emerger como "consecuencias no planeadas" derivadas de la forma en que las personas usan, innovan y combinan diferentes sistemas. Por tanto, implica el análisis de redes, relaciones flujos y circulación, y no de lugares fijos (Sheller y Urry, 2018).

Este paradigma cuestiona los marcos y las narrativas culturales que vinculan la movilidad con la idea de libertad y reconocen las movilidades diferenciadas, incluyendo los ejercicios de desigualdad, de habitar y producir lugar; se reconoce también el control, el conflicto y la vigilancia de estos movimientos (Sheller y Urry, 2018). Por lo tanto, el análisis de la movilidad y el desplazamiento implica considerar la práctica social con sentido, encarnada, modelada por el espacio, la cultura, las relaciones de poder, las estructuras sociales, las tecnologías de transporte, y al mismo tiempo, que las remodela (Urry, 2007, Cresswell, 2010 en Zunino, 2018).

El concepto de migración en tránsito, aplicado para abordar los flujos de población en condiciones de irregularidad ha sido debatido, tanto en su propia definición, como en sus alcances: se ha señalado que no da cuenta de la inestabilidad, circularidad e impredecibilidad de la movilidad, y que ha tenido un énfasis unidireccional (Basock, 2015). Tiene además implicaciones políticas importantes, como su aplicación sesgada que refiere a la migración "no deseada" (Düvell, 2012).

Por tanto, utilizo el término tránsitos migratorios, para destacar la complejidad de los trayectos, de la movilidad y la inmovilidad en condiciones de precariedad. Me refiero a los tránsitos que se realizan de manera irregular, es decir, al margen de las normas de los Estados, sin la autorización necesaria, ni los documentos requeridos por las autoridades para ingresar, transitar o residir en un determinado país. Judith Butler (2009) señala que, la precariedad refiere a un número pequeño de condicionantes en los que se ven concebidos los seres vivos. Por tanto, cualquier elemento vivo puede ser suprimido, sea por voluntad o por accidente, por lo que su supervivencia no se encuentra garantizada de ninguna manera. La precariedad, según

\footnotetext{
2 Por ejemplo: Desplazamientos de cuerpos de personas; movimientos físicos de objetos; viajes virtuales a menudo en tiempo real trascendiendo las distancias; circulación comunicativa a través de mensajes entre personas; y viajes imaginarios (Sheller y Urry, 2018, p. 335)
} 
esta autora, se constituye como una condición inducida; las instituciones sociales y económicas tienen por objetivo reducir las condiciones de precariedad que se originan en la dimensión finita del ser humano.

Sin embargo, la precariedad está políticamente inducida, y representa una condición en la que ciertas partes de las poblaciones quedan expuestas al daño, la violencia y la muerte, al experimentar la carencia de redes de soporte social y económico. Es una exposición que sufren las poblaciones que están arbitrariamente sujetas a la violencia de estado, así como a otras formas de agresión no provocadas por los estados, pero contra las cuales éstos no ofrecen una protección adecuada. Por eso, al mencionar la precariedad se puede hacer alusión, tanto a poblaciones hambrientas o cercanas a una situación de hambruna, como de aquellas dedicadas al trabajo sexual y que tienen que defenderse, tanto de la violencia callejera, como del acoso policial (Butler, 2009).

Se destaca entonces, que la vulnerabilidad es una condición inducida en las poblaciones migrantes en condiciones de irregularidad: “(...) el sistema político democrático acarrea violencia y el sistema económico neoliberal la ejerce de manera cotidiana, con especial énfasis en la población, no sólo vulnerable, sino "vulnerabilizada" por el mismo sistema" (Durand, 2020: 36). Siguiendo a Azaovagh (2017), la precariedad migratoria es la exposición de la población migrante a todo tipo de "heridas" tanto corporales como identitarias, en una situación de desprotección global. Sin embargo, a pesar de esta precariedad impuesta, la agencia social de la población migrante se mantiene, entendida no como la capacidad para tomar decisiones libres y autónomas, "sino como la capacidad de negociar dentro de relaciones de poder y de estructuras de dominación determinadas" (Tinat, 2017, p. 19).

\section{De la etnografía clásica a la etnografía feminista}

Desde el siglo pasado, en diversos contextos geográficos, diversas científicas destacaron la necesidad de desarrollar una mirada de género que pudiera hacer frente al androcentrismo existente en la ciencia. Sciortino (2012) apunta que este androcentrismo constituye el mecanismo por excelencia de la segregación de las mujeres de la ciencia y del conocimiento científico; además de que coloca a los varones y lo masculino en el centro.

El desarrollo de la metodología feminista de acuerdo con Harding (2002) ha permitido el reconocimiento de las experiencias femeninas -o de cuerpos feminizadoscomo una fuente para el análisis social, específicamente en la estructuración de la vida social en su totalidad. En este sentido, esta reflexión busca desarrollar los tres elementos epistémicos propuestos por esta autora: Investigar sobre las experiencias de las mujeres, estar a favor de las mujeres, y situar a la investigación en el mismo plano crítico que el objeto explícito de estudio.

Martha Lamas (1986) ha señalado que la antropología tiene como quid el análisis de la cultura y, por tanto, de las construcciones de género. Si bien reconoce que la mayor parte de los estudios etnográficos han descrito las relaciones entre 
personas, como sujetos insertos en sistemas sexo-genero, existen obras relevantes por la profundización de estos descripciones y análisis como las de Mead, Murdock, Linton. Es desde el feminismo que se cuestiona la "naturalización" de las funciones asignadas a las mujeres, así como de su subordinación (Lamas, 1986). La antropología, desde la década de los setenta del siglo pasado, ha venido desarrollando una suerte de alianza con el feminismo, relación no exenta de contradicciones y conflictos (Gil, 2019) ${ }^{3}$. Esta relación ha tenido efectos en la forma de hacer y pensar la etnografía, método tradicional de la antropología.

La etnografía clásica o convencional, fundamentada a partir de las premisas de Bronislaw Malinowski remite a la larga duración del trabajo de campo, a la objetividad derivada del positivismo, al entendimiento de que "los hechos están en la realidad y sólo necesitan ser reportados por quien investiga” (Castañeda, 2010: 222). Stavenhagen (1971 en Calle y Villareal, 2017) enunció que, desde los sesenta del siglo pasado, la antropología inició un profundo proceso de descolonización, permitiendo que sus marcos teóricos dominantes y los métodos asociados a su ejercicio, experimentaran profundas revisiones; este proceso se extendió a la etnografía, lo que condujo a la modificación de sus bases, a la incorporación de nuevos modos de observar, describir y analizar, dentro y fuera del ámbito académico. Esto representó la necesidad de integrar nuevos contextos y realidades heterogéneas, transnacionales y virtuales.

De acuerdo con Castañeda (2006), la antropología feminista es resultado de estas propuestas críticas, pues permitió debatir a la antropología convencional y a la etnografía en cuatro elementos centrales: el reemplazo de informantes varones por informantes mujeres; la selección de temas específicos de la experiencia de las mujeres que no podrían ser rastreados más que a través de ellas mismas; el reconocimiento de las interacciones entre mujeres en el campo de la investigación empírica y el desmontaje de las posturas esencialistas en torno a las identidades de género.

Carmen Gil (2014) apunta que la antropología feminista se ha preguntado desde hace algunas décadas sobre las implicaciones del antropólogo o antropóloga como conocedor generizado, estableciendo un diálogo intersubjetivo entre el sujeto conocedor y el objeto de conocimiento, entre el yo y el otro desde posiciones políticas situadas.

En este sentido, cabe destacar la reflexividad como cualidad central de la antropología, pero también de la etnografía. Dicha reflexividad, implica entender la situacionalidad de quien investiga, así como la subjetividad que resulta del hecho de ser personas "estudiando" personas. De acuerdo con Haraway (1988) la subjetividad y la visión son multidimensionales, de tal forma que las perspectivas feministas de conocimiento situado no se refieren a una "localización fija en un cuerpo reificado, femenino o de otro tipo, sino a nodos en campos, inflexiones en orientaciones y

\footnotetext{
${ }^{3}$ Carmen Gregorio Gil (2014) señala que "desde los años 80 diferentes autoras han trazado una genealogía feminista a partir del análisis de las propuestas de escritura etnográfica de las antropólogas, véase Stacey (1988), Abu-Lughod (1990), Bell (1993b) y Visweswaran (1997)" (Gregorio, 2014: 300)
} 
responsabilidad por la diferencia en campos semióticos y materiales de significación" (Haraway, 1988: 588).

Las propuestas de la etnografía feminista implican el reconocimiento de la subjetividad y del hecho de que en el trabajo empírico operan el poder, los recursos y las capacidades, por tanto, requiere un constante ejercicio de reflexividad al entender a la cultura como un ámbito de reproducción de las desigualdades sociales que requiere ser analizada, deconstruida y descrita en términos de dominación (Castañeda, 2010). El proceso investigativo implica reconocer también las relaciones de cuerpos sexuados, sexualidad, relaciones de género, de poder, de organización social y de territorialidad, es decir, desarrollar una etnografía encarnada (Castañeda, 2019). Por tanto, esta participación presenta una reflexión de mujeres investigadoras como sujetas cognoscentes y cognoscibles, mostrando una "mirada que analiza los vínculos a través de los cuales el género se entreteje con otras relaciones sociales" (Castañeda, 2010: 228). Se retoma la definición de género de Blázquez (2011) quien apunta a que son atributos que se asocian con dos formas de ser humano, los cuales conforman una serie de símbolos y metáforas que se aplican a personas, cosas, conceptos abstractos: "Lo masculino y lo femenino aparecen relacionados con todo tipo de ocupaciones, destrezas, virtudes, vicios, lugares, objetos, colores, texturas y formas. Los géneros deben considerarse en sus mutuas relaciones. La expresión "relaciones de género" hace referencia a relaciones de poder basadas en la asimetría cultural de hombres y mujeres" (Blázquez, 2011:10).

Castañeda (2010) define a la etnografía como la descripción densa de un observable. Retoma a Clifford Geertz (1991) para caracterizar a este tipo de descripción como el proceso de identificación de estructuras significativas, expresadas a manera de categorías culturales, de estructuras complejas que quien hace etnografía debe captar, explicar e interpretar. Por tanto, no se limita a la recolección de información a través de métodos y técnicas particulares, sino a esta posibilidad de establecer conexiones internas de lo observado que le otorgan significación (Geertz, 1991 en Castañeda, 2010: 221). La etnografía feminista ha permitido reconocer que se trata de una descripción parcial, situada en la mirada de quien observa "a diferencia de las pretensiones de la etnografía más convencional que postula la recreación del carácter holístico de los fenómenos culturales como el objetivo básico de realizar una buena descripción" (Castañeda, 2010: 221).

La cualidad central de la etnografía feminista refiere a que se trata de una

"descripción orientada teóricamente por un andamiaje conceptual feminista en el que la experiencia de las mujeres, junto con la develación de lo femenino está en el centro de la reflexión que conduce la observación...siendo así en el centro de la elaboración epistemológica se coloca la reflexión en torno al ubi de las mujeres y lo femenino en una cultura particular" (Castañeda, 2010: 221).

Se retoma la noción de ubi, de Celia Amorós para referir al lugar que ocupa el sujeto en el mundo, lugar construido ontológica y políticamente, es decir, no solo en un espacio concreto, sino refiere a la construcción filosófica y política que le da sentido. Es decir, el lugar donde quienes hacen antropología construyen el hecho etnográfico con una perspectiva epistemológica, que dará paso al conocimiento antropológico. Es 
el lugar de la práctica e interacción antropológica, en el que los diferentes actores despliegan los hechos de la cultura en toda su complejidad. Por lo tanto, es el punto nodal en el que antropólogas y antropólogos son capaces de relacionar empiria y teoría (Castañeda, 2019).

Por tanto, interesa reflexionar sobre el tipo de etnografía realizada en el tema de tránsitos precarios masculinizados, entendiendo a las etnógrafas como sujetas de acción, encarnadas en cuerpos que experimentan, sienten, y desarrollan conocimiento; comprendiendo que no existe una única metodología feminista, ni una sola etnografía feminista, pues se rechaza la noción de métodos estandarizados, que busquen la universalidad, la generalización, sino más bien desarrollar una investigación flexible, que se adapte a la realidad que se busca analizar.

\section{La Sagrada Familia como el espacio de la investigación.}

El albergue La Sagrada Familia se ubica en la ciudad de Apizaco, Tlaxcala. Esta ciudad, representa un punto intermedio en la ruta de los centroamericanos, que se dirigen hacia la frontera norte y constituye un nodo importante en la vía ferroviaria, pues es la sede de la Terminal de ferrocarril Ferrosur que conecta con la de Lechería. Se encuentra en la parte media de la ruta, entre Orizaba, Veracruz y el Estado de México, en la bifurcación de la ruta hacia el estado de Puebla o Lechería y, además, es uno de los primeros puntos fuera del sur del país (Ver imagen 1).

Comparativamente con otros estados del país, Tlaxcala tiene una menor proporción de personas migrantes en tránsito, una razón es que el descenso del tren en esta parada no implica una decisión estratégica en la gestión del tiempo, por lo que algunos prefieren seguir al siguiente destino. Si bien esta ciudad es un sitio de descanso no obligado, es cada vez más frecuentado, debido a la necesidad de alimentarse, asearse, comunicarse con su familia o bien, sanarse de alguna herida $o$ enfermedad.

El arribo a esta ciudad representa el fin de la zona sur y es observada por los migrantes como una región "más tranquila", en comparación con la zona meridional del país. Sin embargo, también reporta riesgos importantes: existe una zona de trata reconocida en la parte sur de Tlaxcala y se ubica cerca del triangulo rojo: una región en Puebla donde se ubican los denominados huachicoleros ${ }^{4}$. Además, el número de redadas por parte del Instituto Nacional de Migración (INM) ha sido una constante en esta zona.

El flujo migratorio de centroamericanos por Apizaco ha adquirido visibilidad desde hace más de una década, y ha cobrado mayor importancia a partir del deterioro de las condiciones de transito. Este deterioro se relaciona con las acciones emprendidas por el INM y por la compañía Ferrosur, que, en el año 2012, un año después de la edificación del albergue y bajo el amparo del Plan Integral Frontera Sur, instaló una serie de postes de concreto que impiden abordar o descender de los

\footnotetext{
${ }^{4}$ Delincuente que se dedica a robar gasolina perforando los oleoductos que la conducen (El Colegio de México (COLMEX), 2020)
} 
vagones en movimiento, obstaculizando el ingreso al albergue y la ayuda humanitaria (Ver imagen 2). El 11 de septiembre de 2019, personas desconocidas ingresaron a las oficinas del albergue para sustraer materiales, bienes, allanar la propiedad e incendiar las instalaciones.

\section{Imagen 1. El estado de Tlaxcala}

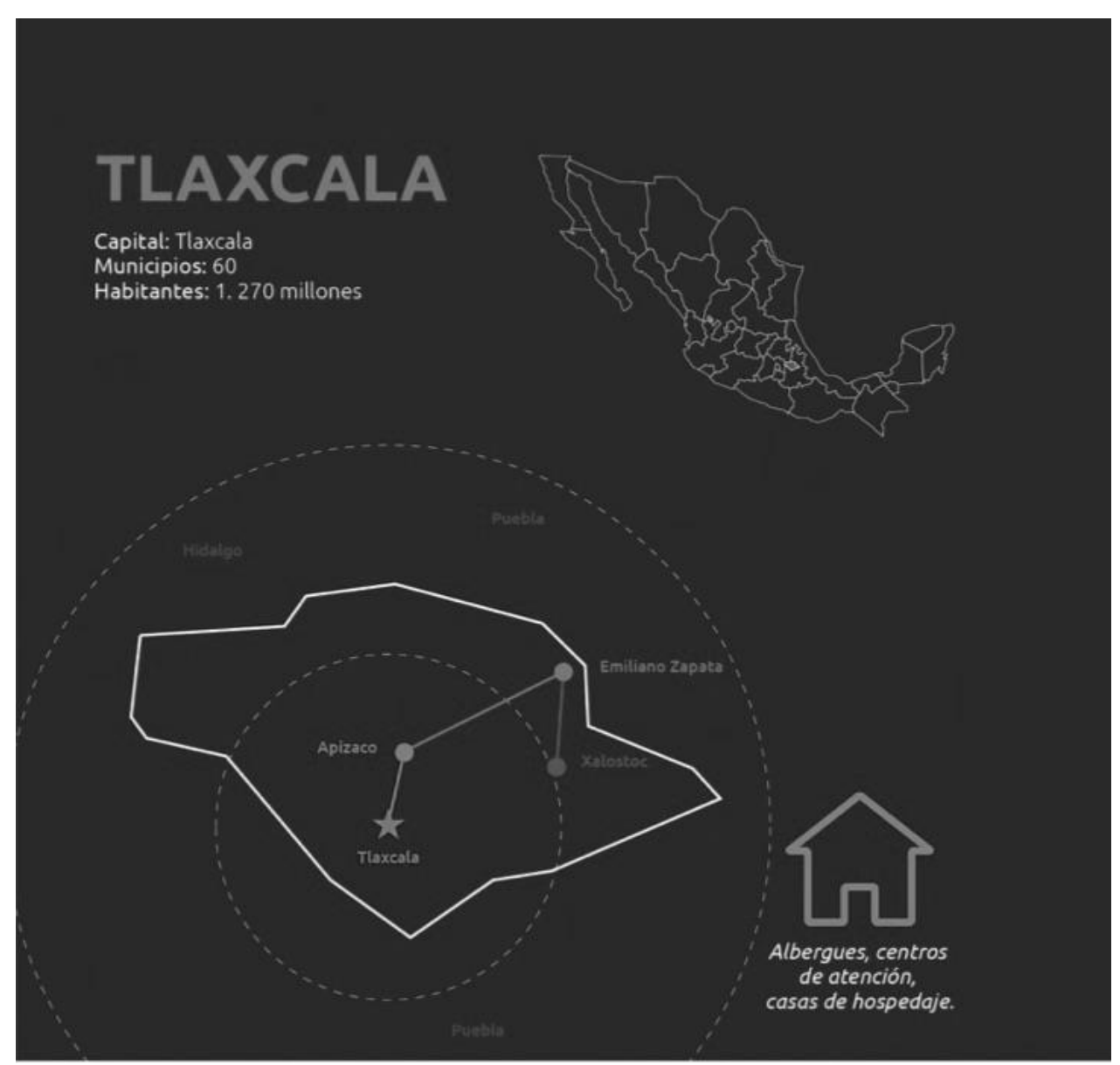

Fuente: Organización Internacional para las Migraciones (2018)

La versión de la empresa es que los postes son para proteger la seguridad de sus vagones ante ataques de la delincuencia y la defensa del derecho de vía. De manera paralela, se han difundido mensajes y notas periodísticas que criminalizan a la población migrante al acusarlos de participar en los hechos delictivos -como los asaltos a sus vagones-, con lo que se refuerza la estigmatización y la intolerancia. Estos postes han generado que al menos seis migrantes hayan sufrido mutilaciones en extremidades y aproximadamente 40 más hayan tenido accidentes considerables (Ver imagen 3).

En este albergue se observa mayoritariamente varones hondureños, aunque se ha incrementado el flujo de familias, mujeres y menores no acompañados, que llevan en promedio 15 días viajando, en tren o caminando. En 2019, a partir de las políticas migratorias de la administración de López Obrador, los días de viaje han aumentado pasando a ser casi 25 días caminando o en tren. 


\section{Imagen 2. Las fronteras internas}

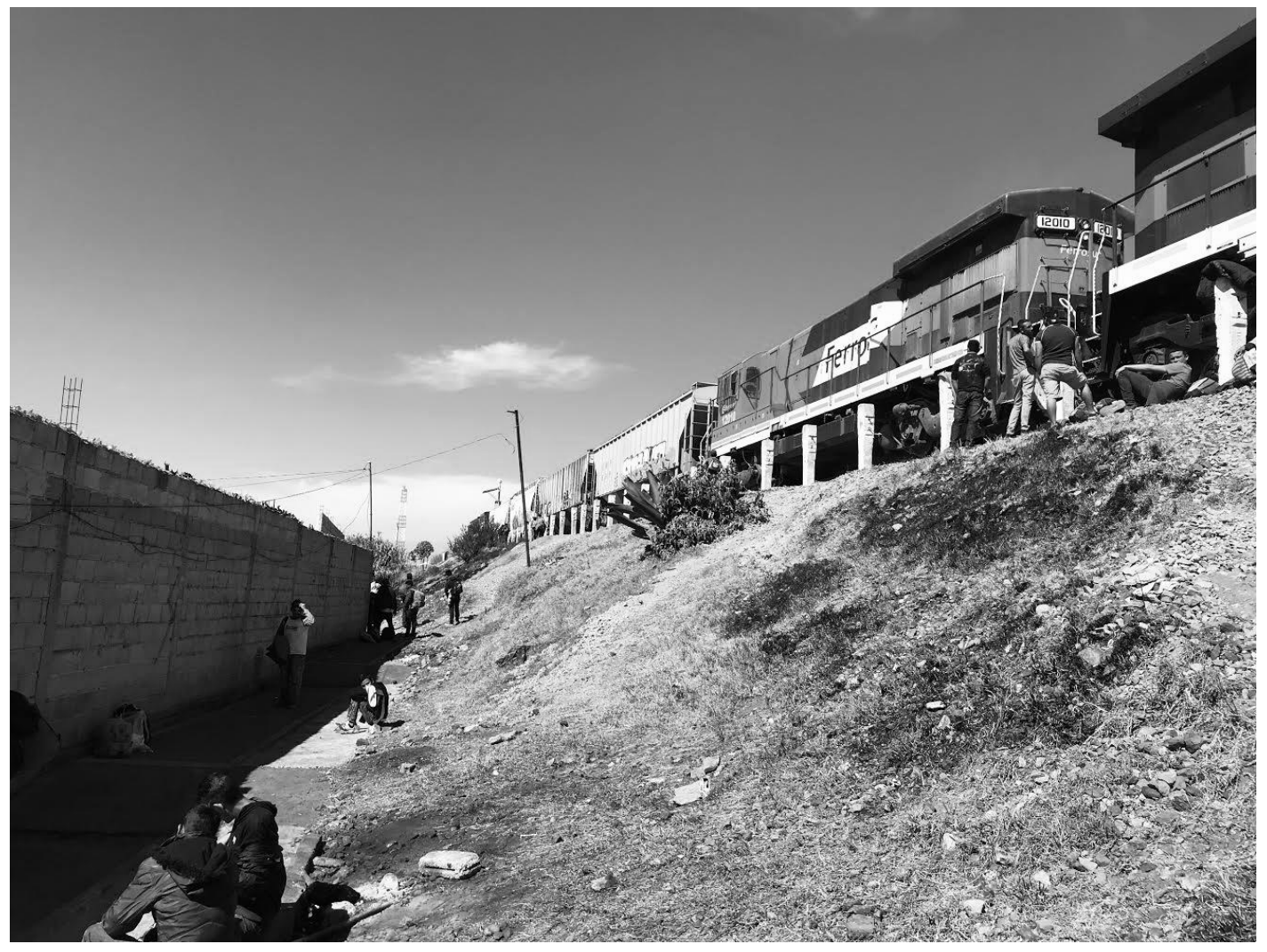

Fuente: Toledo (2018)

Para 2019 el director del albergue señalaba:

"En estas circunstancias, el albergue representa para quienes migran un espacio de descanso y seguridad. Aquí acuden, principalmente, personas provenientes de Honduras, Guatemala, El Salvador y Nicaragua. Según las estadísticas del albergue, en 2018 se alojaron al menos 5121 personas, que se suman a las 35 mil atendidas en años anteriores (ASAFAM, 2019)" (Luna, 2019: 110).

Las personas que arriban al albergue manifiestan un agotamiento físico y emocional; y que incluye hambre, cansancio; malestares como tener la piel quemada por el sol o por el frío, ampollas y ámpulas en los pies y en las manos (originados por las largas caminatas o por intentar subir al tren); además de condiciones de salud originadas por el propio tránsito: deshidratación, estrés, estrés postraumático, infecciones en diversas partes del cuerpo, gripes, heridas. Algunos padecen enfermedades y trastornos adquiridos antes del inicio de su viaje, como desnutrición, diabetes, asma, esquemas de vacunación incompletos, hipertensión, problemas neurológicos, depresión, entre otros que se agravan con las condiciones del trayecto. Un elemento importante tiene que ver con la imposibilidad de descansar por la 
amenaza constante de ser víctimas de la delincuencia, de los policías coludidos, del INM y en el caso de los que viajan en el tren, por el miedo de caer.

\section{Imagen 3. Los postes}

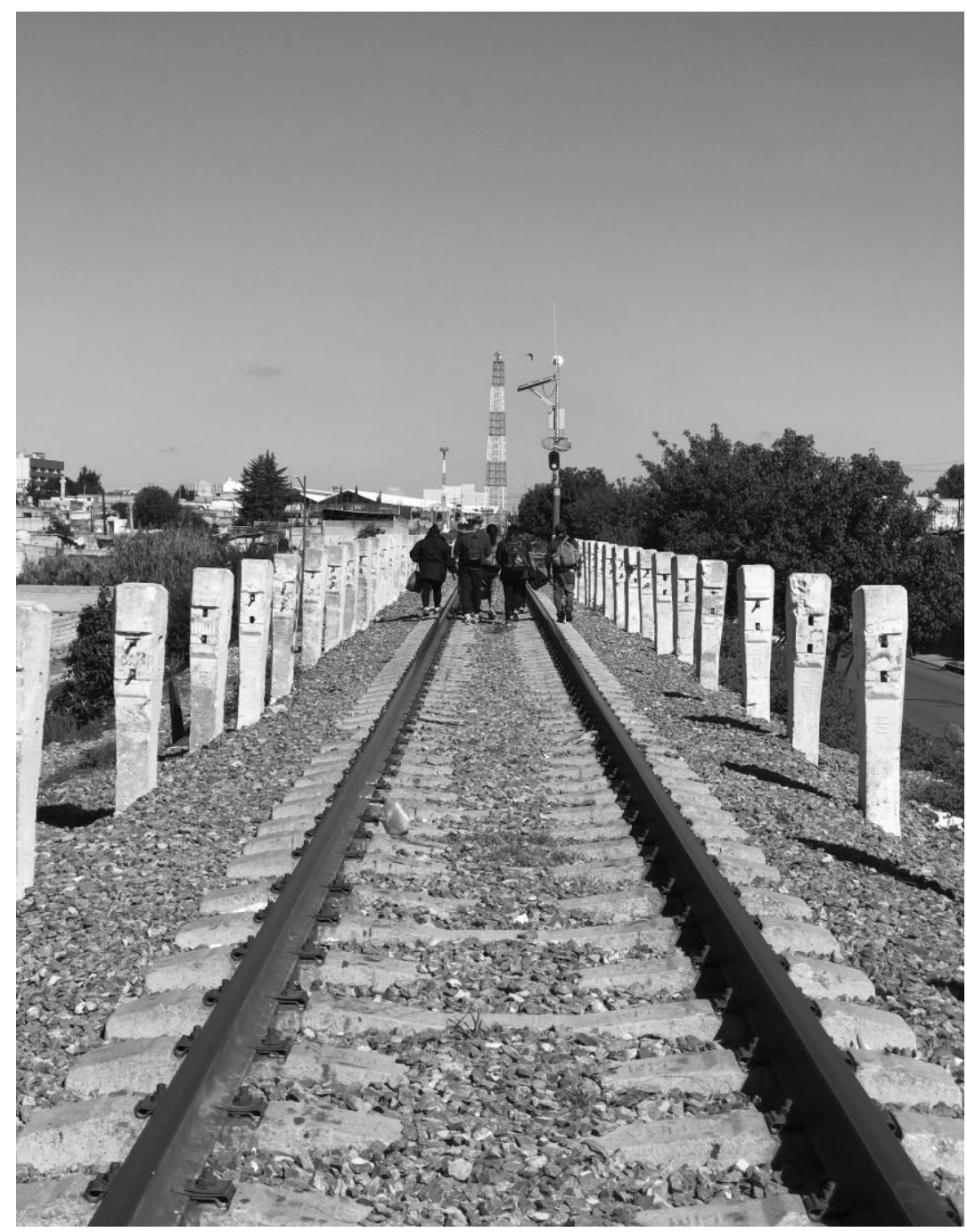

Fuente: Toledo (2018)

Es importante señalar que el estado de Tlaxcala no constituyó un punto en el trayecto de las caravanas de migrantes del $2018^{5}$, pues dentro de la zona del Altiplano éstas circularon por Puebla y la Ciudad de México. A Apizaco llegaron los rezagados o gente que se apartó de las caravanas, también quienes no tuvieron la intención de

\footnotetext{
${ }^{5}$ Las caravanas de migrantes se refieren a la presencia "masiva" de migrantes en condiciones irregulares, que buscaban llegar a Estados Unidos atravesando México. Si bien ya existían caravanas, como las de las madres centroamericanas que buscan a sus hijos e hijas, las caravanas del 2018 inaguraron una nueva estrategia de movilizarse en colectivo para hacer frente a los riesgos que han hecho que el corredor migratorio mesoamericano que integra los países de Centroamérica-MéxicoEstados Unidos, sea uno de los más mortales.
} 
participar. Sin embargo, el flujo de migrantes aumentó de manera considerable. Las caravanas trajeron como consecuencia no deseada, el aumento de la discriminación en el espacio local.

En junio de 2019, las autoridades municipales colocaron una malla ciclónica con púas sobre la calle que funciona como entrada principal al albergue, la cual limita el acceso e impide la movilidad continua de las personas migrantes que pasan por la entidad. Las autoridades señalaron que dicha malla se instaló en respuesta a las solicitudes de algunos vecinos del albergue, quienes argumentan el incremento de la delincuencia cometida supuestamente, por personas migrantes, así como el "mal aspecto" de personas descansando sobre las banquetas (Ver imagen 4). El 11 de septiembre del 2019 las oficinas del albergue fueron atacadas por personas desconocidas, que allanaron, robaron bienes y materiales, además de incendiar las instalaciones.

El trabajo de campo se llevó a cabo dentro de las instalaciones del albergue, como una medida de seguridad para quienes nos encontramos desarrollando investigación en este lugar, donde múltiples factores -crimen organizado, violencia, asaltos, conflictos con vecinos, la constante presencia de agentes del Instituto Nacional de Migración (INM) de la policía municipal- hacen de la zona un lugar peligroso.

\section{Etnografiar a las etnógrafas ${ }^{6}$}

En la parte inicial del texto se apuntó a que el grupo de investigación ha estado conformado mayoritariamente por mujeres, por lo que considero necesario plantear una reflexión sobre el ser mujeres que realizan trabajo de campo en condiciones de riesgo. Para hacer esta reflexión, retomo las experiencias de algunas participantes en el proyecto: María, Rosa, Gabriela, Angie, Elisa ${ }^{7}$, así como mi propia experiencia. Los temas de investigación versaron sobre discapacidad motriz adquirida; masculinidad, desaparición forzada de migrantes centroamericanos, violencia y mujeres migrantes centroamericanas. Todas desde el campo de las Ciencias de la Familia. Los rangos de tiempo de trabajo de campo van desde dos años, año cuatro meses, tres y dos meses. Quienes menos trabajo de campo realizaron debieron suspenderlo por la presencia de la COVID-19.

En todos los casos se realizó trabajo de campo dentro del albergue, aunque también se hicieron visitas al Decanal Guadalupano en Tierra Blanca y con Las Patronas en Amatlán de los Reyes en Veracruz, y en el albergue del municipio de Emiliano Zapata en Hidalgo. Se desarrolló observación participante a través de la ejecución de voluntariado realizando tareas como: registros de ingreso de la población recibida, entrega de artículos de higiene y alimentos, preparación de alimentos, llenado de solicitudes para retorno voluntario, atención a curaciones, supervisión de llamadas gratuitas, entrega de ropa, apoyo en la cocina, clasificación de medicamentos, así como la realización de algunas actividades lúdicas y de

\footnotetext{
${ }^{6}$ Este título es una réplica del trabajo elaborado por Martha Patricia Castañeda (2019).

${ }^{7}$ Los nombres han sido modificados
} 
recreación en los tiempos de espera (juegos de mesa o dinámicas de integración). En cuanto a la investigación, se realizó observación participante y directa, entrevistas a profundidad, diario de campo.

Cuatro de las seis participantes señalaron haber sentido miedo durante el trabajo de campo; una de ellas dijo que no sintió miedo como tal, pero que sí había "actividades en las que prefería estar acompañada" (Elisa, entrevista, 2020). Otra más dijo no haber sentido miedo (ella estuvo dos meses únicamente), señaló que el hecho de no sentirlo tenía que ver con el rapport que estableció dentro del albergue, así como con el hecho de que el personal otorgaba respeto y poder a las mujeres.

Las actividades que más les generaron esta sensación de miedo fueron exigirles a los migrantes no usar el celular dentro del albergue (pues es una norma de la institución). María apunta que se debe a "su falta de carácter fuerte... era una debilidad para no entrometerme" (María, entrevista 2020). Otra más señala que "cuando se tenía que entregar ropa" (Angie, entrevista 2020) y cuando tenían que "entregar ropa a los migrantes, específicamente a los hombres" (Rosa entrevista 2020). Gabriela señala "Al escuchar diversas historias, en ocasiones me daba miedo seguir preguntando a profundidad, también por los cuestionamientos y reproches que en ocasiones surgían, no directamente hacia mí, pero si era notable el enojo en las personas hacia autoridades y terceras personas" (Gabriela, entrevista 2020). Las historias de secuestros, trabajo forzado y desapariciones forzadas alimentaban el temor y la incertidumbre.

Respecto al hecho de ser mujer, ellas señalan que la posibilidad de sufrir un ataque sexual siempre constituía un riesgo, así como el hecho de estar solas con más varones: "Por el hecho de estar rodeada de personas que mayormente eran varones. Porque en su mayoría los migrantes son hombres y en ocasiones me tocaba estar sola en alguna área y algunos de ellos (no todos), hacían comentarios de doble sentido y algunos se portaban groseros. Los comentarios de los migrantes eran un tipo de acoso" (Elisa, entrevista, 2020). "Una vez me quedé sola en el albergue y ya habían registros de que en ocasiones los migrantes se querían propasar con las voluntarias" (María, entrevista, 2020); "Cuando me encontraba sola en el albergue, regularmente cuando no había más encargados del turno que yo y la persona encargada de las llaves, que en ese tiempo persona del sexo masculino" (Gabriela, entrevista, 2020). "Porque al no contar el albergue con medidas de seguridad y estar sola los días domingos me hacían estar en una condición de vulnerabilidad" (Brenda, entrevista, 2020). 
Imagen 4. La malla

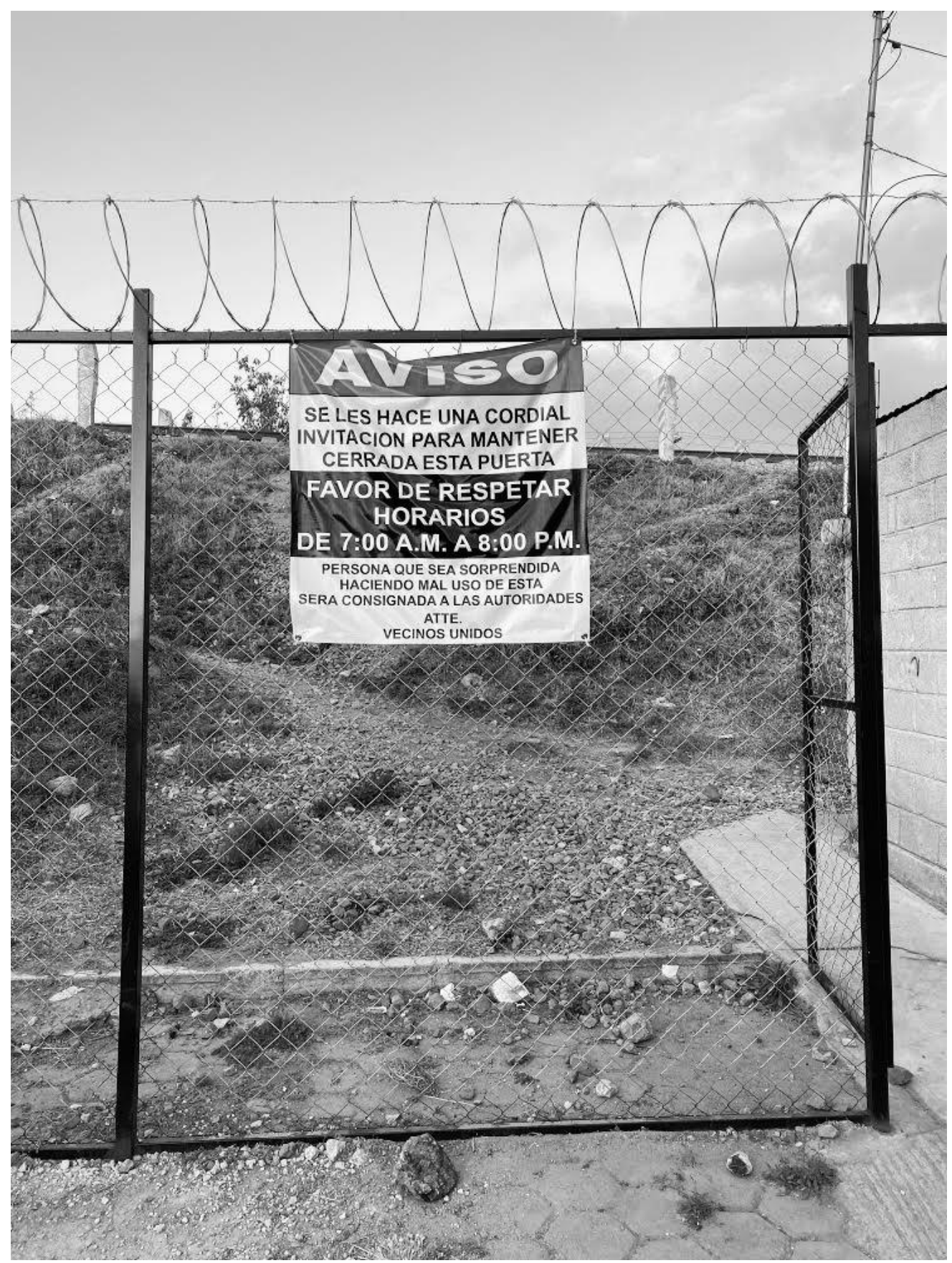

Fuente: Toledo (2019)

Quienes sí sintieron miedo, señalan que se sentían encerradas, y frente a la posibilidad de ser acosadas, Rosa afirma "El hecho de que las historias sean violentas y de muertes en ocasiones me causaba un poco de miedo, también porque al recordar historias pasadas no se sabe cómo reaccionarán las personas y yo me encontraba sola con ellas, mientras hacía entrevistas" (Rosa, entrevista 2020). María comentó, "Considero que esto se debió a una ocasión en especifico, en la cual, yo me encontraba sola, ordenando la ropa y uno de los migrantes se comportó de una 
manera agresiva y prepotente al pedirme que le diera una playera y me sentí intimidada" (María, entrevista, 2020).

Algunas actividades que les incomodaban tenían que ver con las propias condiciones operativas del albergue, por ejemplo, el temor a las parrillas de gas que daban flamazos. Una de las limitaciones al acercase a los varones, fue que se temía que pensaran que la intención de acercarse era "distinta" (Elisa, entrevista, 2020) y que "lo tomaban para otra cosa" (María, entrevista, 2020), es decir, podía relacionarse a cuestiones de índole sexual. Por ejemplo, en una ocasión "porque la persona a la cual entrevistaba comenzó a insinuar cosas inapropiadas, por la situación tuve que pedirle que se limitara a contestar lo que estaba preguntando" (María, entrevista, 2020). Había comentarios que nos incomodaban, por ejemplo, cuando decían que las mexicanas eran guapas o que buscaban a alguna para casarse, algunas se incomodan con ciertas preguntas, por ejemplo, sí tenían novio, sí estaban casadas, o sí no le gustaban los hombres hondureños.

Respecto a los riesgos, las participantes han señalado la inseguridad de la zona, pues es un lugar solitario y sin vigilancia, dentro del albergue también se consideró que existían pocas medidas de seguridad. A esto se añaden los ataques de los vecinos "como se trabajó con una comunidad marginada, había una desprotección ante los ataques de vecinos" (Gabriela, entrevista, 2020). Algunos migrantes "comentaban que cerca del albergue vendían droga, específicamente en un punto que era sospechoso y justo ahí era la parada del transporte público. $Y$ el transporte tardaba mucho en pasar" (Elisa, entrevista, 2020). Una de las participantes señala el riesgo al que se sintió expuesta:

Quizá podría nombrar uno, cuando llegó una mujer acompañada de dos hombres, los tres provenían de Guatemala y argumentaban que los venían siguiendo, un cartel en específico, su tiempo de estancia fue corto y realmente ingresaron para curar sus heridas (ya que los habían golpeado y secuestrado en Veracruz) y recuperarse físicamente. Ese fue un riesgo que sentí por el hecho de que argumentaban que los venían siguiendo porque habían logrado escapar (Rosa, entrevista, 2020)

Un elemento que generaba incertidumbre era la posibilidad de presenciar o ser víctima de asaltos. También el hecho de quedarse a solas "con personas que no sabes cómo van a reaccionar o qué actitudes pueden tomar" (Brenda, entrevista, 2020), o bien, estar expuestas a robos, la falta de personal, no contar con espacios seguros donde guardar dinero o cosas personales (a otra estudiante que participó en el proyecto, le robaron su celular).

Consideran también que no existen medidas mínimas de seguridad sobre el acceso de las personas, de las amenazas de migrantes y vecinos, así como una falta de personal voluntario sobre todo el domingo: "A veces me tocaba estar sola como responsable y solo estaban hombres en el albergue. Me sentía vulnerable a cualquier ataque" (Brenda, entrevista, 2020).

Entre los conflictos que se señalan por parte de las participantes se distinguen algunos desencuentros con el personal voluntario, tanto por el trato a la población 
migrante, por la toma de decisiones o por la interacción constante en contextos de incertidumbre. Por ejemplo, María señala:

Hubo una ocasión en la que llegó un hombre que días después de salir del albergue cayó en las vías y tuvo que ser ingresado en el hospital. Cuando lo dieron de alta llamaron al Instituto (Nacional) de Migración y al albergue, a mi me tocó acompañar a la persona que fue a recogerlo para llevarlo de vuelta al albergue y que ahí se recuperara. Sin embargo, el INM llegó primero y fue el instituto el que se hizo cargo del egreso, el hombre lloraba y suplicaba que lo ayudáramos, pero el IM decidió deportarlo. Él creyó que nosotros colaboramos con el Instituto (María, entrevista, 2020).

Sobre el trabajo de campo es importante mencionar que, como responsable técnica del proyecto, decidí establecer algunas pautas de seguridad. Una de ellas fue circunscribir la realización de entrevistas y observación dentro del albergue. Esto tiene que ver con varios hechos ocurridos durante la observación participante. Una de mis tareas era repartir la ropa, un día me tocó darle a una mujer de 35 años, visiblemente abrumada. Al darle la ropa, ella me preguntó si podía probársela porque estaba muy grande, al quitarse el pants observé que tenía muchos moretones y raspones, se dio cuenta que la miré y rompió en llanto. Me contó que, al subir a su hija y a su hermana al tren, ella no lo logró y corrió para tratar de alcanzarlo. Cuando se dio cuenta, estaba sola en la vía, un hombre llegó y comenzó a manosearla, ella trató de defenderse y el hombre la golpeó varias veces. Sin embargo, ella logró picarle un ojo "como traigo las uñas largas se las enterré en un ojo", logró escapar e ingresar al albergue, donde se realizaron gestiones para encontrar a su familia.

Además, supimos de un caso de una familia de nueve personas que fue detenida con violencia en las inmediaciones del albergue, exactamente sobre las vías, poco después de haberlos atendido y se les diera la bendición al emprender su viaje. En otra ocasión, salimos del albergue a comprar a una tienda ubicada a pocas cuadras. Ingresamos y decidimos quedarnos unos minutos fuera de la tienda, cuando nos dimos cuenta, estábamos rodeadas por agentes del INM, ellos después de observarnos y escuchar nuestro acento, decidieron retirarse. La incertidumbre generada por estas situaciones, aunadas al hecho de ser la responsable del equipo, me llevaron a tomar la decisión de restringir nuestro trabajo a las instalaciones del albergue. Esta decisión implicó la incapacidad de desarrollar etnografía multisituada, es decir, de aquella que hace uso de distintos espacios/lugares interrelacionados para la etnografía y la observación participante (Marcus, 1995).

Los riesgos que se presentan en la zona también tienen que ver con las redes de trata que operan en el estado de Tlaxcala, existen versiones que en la colonia hay enganchadores, además, en algunos comercios venden drogas; a esto se añade la actitud de los vecinos, unido al riesgo latente de que ingrese de algún coyote/pollero o enganchador al albergue. Ante estos riesgos, asumimos diversas estrategias: acompañarnos para no circular solas en las inmediaciones, participar de un grupo de 
whatsapp ${ }^{8}$ para el personal voluntario, "realizar algunas actividades siempre en compañía de algún compañero o compañera del albergue" (María, entrevista, 2020); "no ingresar con cosas de valor al albergue" (Rosa, entrevista, 2020); "no pasar número (telefónico) y redes sociales a los migrantes, respetar los horarios para ingresar al albergue y tener comunicación constante con algún compañero o compañera" (Gabriela, entrevista, 2020). También evitar salir "muy tarde" del albergue, caminar en calles donde se observara la presencia de personas, incluso hay quien señala "mantener la puerta cerrada de la cocina para evitar el acceso a los cuchillos, tratar de estar siempre acompañada y tener el teléfono siempre cerca por si pasaba algo" (Brenda, entrevista, 2020).

En cuanto a las implicaciones de hacer trabajo de campo en este contexto, las participantes sí consideran que estuvo limitado por el hecho de ser mujer: "Puesto que la gente que se trataba en su mayoría era masculina, había tareas que no eran compatibles" (Elisa, entrevista, 2020). "Las personas no se acercan y no le cuentan las mismas cosas a una mujer que a un hombre" (Gabriela, entrevista, 2020); "noté que los migrantes se expresaban distinto con una persona igual a su sexo masculino que cuando se sentaban a dialogar conmigo o con alguna otra compañera. Generalmente cuando se acercaban a mi era por algún motivo, duda de medicamentos o acceso alguna área" (María, entrevista, 2020); Brenda afirma que una de las limitaciones fue el hecho de "no acceder a espacios" de hombres" y además, "la información se filtraba según como te percibían como mujer: buena onda, guapa, voluntaria, etc." (Brenda, entrevista, 2020).

Para quienes afirman que el hecho de ser mujer no representó una limitación refieren a la feminización del trabajo del voluntariado: "En el contexto donde se realizó trabajo de campo y voluntariado, considero que es un espacio que se encuentra feminizado por las actividades que se realizan, y debido a ello podía existir acercamiento directo a los migrantes" (Elisa, entrevista, 2020).

Dos de las participantes dicen que el hecho de ser mujer les facilitó su trabajo: "Vi que las mujeres transmitían confianza, tanto para los hombres como para las mujeres" y "Para conseguir las entrevistas eran más accesibles los migrantes más jóvenes que las personas con mayor edad" (María, entrevista, 2020). Para quienes señalan que no les reportó ninguna facilidad, se debe que consideran que existirán dificultades al realizar trabajo de campo, o como Gabriela que señala que "no me pareció que para alguna actividad diera más facilidad, al contrario, en algunas era una limitante, como el acercamiento y confianza de las personas hacia mí".

Al preguntarles si consideran que su trabajo de campo habría sido diferente si su género fuera distinto, todas señalaron que sí, argumentando que existiría más confianza para entablar diálogo con los hombres y temas diferentes, o quizá tendrían menos miedo o habría menos riesgos, además que destacan el género como condicionante de las relaciones en campo. "En el supuesto a que la información recabada y expresada por los migrantes hubiera resultado menos abierta por las

\footnotetext{
${ }^{8}$ Aplicación de internet que permite la interacción de un gran grupo de personas a la vez, mediante los grupos.
} 
cuestiones de las emociones generadas y expresadas durante las entrevistas" (Gabriela, entrevista, 2020). "El albergue, al ser un sitio donde llega población mayoritariamente masculina, si eres hombre hay una condición de respeto, entre pares o bien, una identificación por género" (Brenda, entrevista, 2020).

Como consecuencia de esto, apuntan que los resultados de sus investigaciones pudieron ser distintos: Pues se tendría información diferente ya que posiblemente se tocarían otros temas con más facilidad y confianza. Por las formas de interacción que se establecen en las relaciones y desde el lugar donde uno se posiciona como investigador/a. Creo que lo único que cambiaria sería la amplitud de los datos, hubiera logrado recabar más datos dentro de las historias que contaban. "Porque al no haber obtenido respuestas en las que los migrantes expresaran sus emociones ante la perdida de una extremidad de su cuerpo, el resultado solo se habría planteado con respuesta de si y no" (María, entrevista, 2020); "Acceder a los espacios masculinizados o a las lecturas del espacio desde "el ser hombre" seguramente arrojan otras perspectivas" (Brenda, entrevista, 2020).

\section{Lo efímero en campo.}

El título de este artículo tiene que ver con la propia definición del adjetivo efímero: "pasajero o de corta duración" (Real Academia de la Lengua Española (RAE), 2020) y las cualidades del tránsito de población hondureña por el centro del país, como un movimiento no solo pasajero, sino que también busca invisibilizarse para no ser sujetos de violaciones a sus derechos humanos. Zuzino señala que es necesario comprender que lo transitorio, fugaz o efímero que caracteriza a la modernidad urbana (Frisby, 2001 en Zuzino, 2018): "aun cuando la experiencia sea impersonal y fugaz tiene un significado, produce cultura y es formada por ésta. Esa fugacidad de las relaciones o la distancia social puede ser representada y experimentada como un problema, quizás para algunos produzca angustia, pero para otros es un espacio de individualidad, relax, libertad" (Zuzino, 2018, p. 39). A partir de esta premisa es que planteo un análisis del tiempo en la ejecución de la etnografía.

La cuestión del tiempo en la etnografía ha tenido varias vetas analíticas: el cambio de largas estancias en campo a una reducción del tiempo, en razón de las limitantes que imponen las instituciones académicas o financieras Silva y Burgos (2011). Están también quienes establecen el tiempo mínimo necesario para realizar etnografía, por ejemplo, que debe durar 12 meses, dos años, incluso hay algunas propuestas como el "tiempo comprimido"9 (Jeffrey y Troman, 2004). Otra veta es la antropología del tiempo (Gell, 1992; Vargas, 2007). En esta propuesta no me enfoco en la duración del trabajo de campo, ni a la antropología del tiempo; sino a las cualidades de la población estudiada, una población evanescente, móvil. El tiempo fue una de las limitantes señaladas por las participantes para el desarrollo del trabajo de campo.

\footnotetext{
${ }^{9}$ Este modo comprimido refiere a un corto período de intensa investigación etnográfica en el que los investigadores habitan un sitio de investigación casi de forma permanente durante unos pocos días hasta un mes.
} 
Inicialmente, la población que acudía al albergue podía estar por 48 horas, sin embargo, dado el aumento en el flujo de migrantes, se redujo a 24 horas (excepto para personas que tuvieran niños, estuvieran enfermos, o vinieran con sus familiares). A diferencia de otros albergues, en esta institución los migrantes pueden salir y entrar (excepto por la noche, alrededor de las 21:00 hrs. se limita el acceso, y es a partir de las seis o siete de la mañana que se permite la salida o nuevos ingresos). El hecho de permitirles la salida tiene que ver con que en términos formales, los agentes migratorios no pueden detenerlos en las inmediaciones de los albergues ${ }^{10}$, esto para ellos implica mayor libertad, pues como lo señala José: "en otros albergues nos tienen como encarcelados" (José, hondureño, entrevista). Aunque se han dado casos en que, "en la misma esquina de la calle han hecho detenciones, ya ve que cuando fueron a dejar la basura, ahí los agarraron" (Pedro, hondureño, charla informal).

En ocasiones, los migrantes escuchaban el tren y salían corriendo, muchas veces sin completar el registro, dejando su plato de comida, a medio vestir o dejando sus pocas pertenencias. Por lo que el tiempo de su estadía es totalmente variable. Esto representó una dificultad para recabar información, además de la falta de espacios para la realización de entrevistas y la asignación de tareas dentro del voluntariado, pues en ocasiones no se podían hacer entrevistas debido a las actividades que debían realizar.

El voluntariado y la participación en tareas revirtió la dificultad de establecer el rapport en estas condiciones. Tomamos la decisión de realizar cualquier tarea que se nos pidiera, aunque es importante señalar que hubo algunas actividades que nunca se nos asignaron, como, por ejemplo, el aseo de los baños ${ }^{11}$. La observación participante cobró relevancia y de igual manera se recurrió al registro de charlas informales que sirvieron para completar el trabajo de campo realizado.

Un elemento que requiere una mención aparte, son las implicaciones emocionales del trabajo de campo, las despedidas a la población migrante fueron sumamente dolorosas y difíciles, sobretodo de aquellos con los que pudimos establecer relaciones significativas en poco tiempo, pues asumíamos que era muy poco probable volvernos a encontrar. En varias ocasiones compartimos la sensación de impotencia, y debimos pedir "tiempo, fuera", compartir el llanto, alegrarnos con el sonido del tren, correr para gritarles y hacerles señales con las manos a quienes viajaban en él, para que supieran que en el albergue había comida y medicina; escuchar las llamadas telefónicas a sus familias, también resultaba complejo. A diferencia de los voluntarios del equipo del albergue, nosotras decidimos sentarnos a comer con la población migrante los mismos alimentos. Aprendimos a cocinar en

\footnotetext{
10 El artículo 76 de la Ley de Migración establece el derecho a no ser detenidos en las inmediaciones o dentro de albergues: Las autoridades migratorias no tienen la atribución conferida por ley de realizar detenciones de personas migrantes que se encuentren alojados o en las inmediaciones en albergues con este fin patrocinados por Asociaciones Civiles o personas que presten asistencia humanitaria a los mismos. El INM podrá realizar visitas de verificación migratoria en los lugares donde se encuentre migrantes albergados por organizaciones de la sociedad civil o personas que realicen actos humanitarios, de asistencia o de protección a los migrantes.

11 Siguiendo a Devetter (2013) la limpieza de los baños aparece como un elemento concreto en la categorización de trabajo sucio y de lo que Roberts (1997) denomina "menial work" (trabajo de baja categoría) (Toledo, 2014).
} 
grandes proporciones, a curar heridas, a escuchar, a encontrarnos y reconocernos como mujeres etnógrafas.

\section{Conclusiones}

Esta participación tuvo como eje mostrar una reflexión del trabajo de campo realizado en el albergue La Sagrada Familia en la ciudad de Apizaco, Tlaxcala en dos elementos: las experiencias etnográficas como mujeres investigadoras, y el papel del tiempo en la conformación de los sujetos de estudio. Interesó establecer las experiencias de las etnógrafas y sus lugares de enunciación (Haraway, 1991), desvelando las relaciones de poder en campo, específicamente en torno a la violencia y al género; una perspectiva que, por supuesto, no busca ser victimizante, ni estigmatizante de la población masculina centroamericana, sino que busca abonar a la reflexividad metodológica.

Sobre la propia etnografía feminista realizada en espacios masculinizados, podría sugerir la ejecución del trabajo de campo en equipos de investigación que incluyan varones y población no genéricamente binaria como piezas claves para la aproximación al estudio de los varones, para desarrollar procesos de acompañamiento y enriquecer los diálogos y las narrativas. Resulta importante integrar miradas contrastantes, pero sobre todo que permitan desarrollar procesos reflexivos en el trabajo de campo. En esta participación se destacan posiciones antagónicas que perciben como ventaja el hecho de ser mujeres y aquellas quienes lo observaron como un obstáculo, por tanto, considero necesario dialogar sobre los lugares de enunciación y las experiencias individuales y colectivas como sujetas cognoscentes y cognoscibles.

Se considera que esta reflexión desde el género resulta central toda vez que analizamos un flujo masculinizado, cuyas experiencias se producen en un ámbito de migración irregular, bajo un contexto de políticas basadas en la seguridad nacional, que crean y recrean espacios de miedo, muerte e incertidumbre, cuyos efectos han sido paliados por organizaciones de la sociedad civil (laicas y religiosas). Ante un Estado mexicano indolente, estas instituciones y su personal voluntario han debido asumir las consecuencias e implicaciones de estas políticas. Es importante destacar que mucha de la población voluntaria en asociaciones civiles se constituye por mujeres, además de que existe una buena cantidad de etnógrafas que abordan estos temas, por tanto, queda pendiente el siguiente cuestionamiento ¿Cuál es el carácter político de esta etnografía feminista desde la movilidad?

\section{Referencias}

Azaovagh de la Rosa, Anisa (2017). Ética, precariedad y resistencia migratoria. Astrolabio: revista internacional de filosofía, (19), 259-68. https://www.raco.cat/index.php/Astrolabio/article/view/318868 
Basok, Tanya, Bélanger, Danièle, Rojas Wiesner, Martha Luz, Candiz, Guillermo (2015) Rethinking Transit Migration Precarity, Mobility and self- making in México. New York: Palgrave MacMillan UK.

Blázquez Graf, Norma (2011) El retorno de las brujas. Incorporación, aportaciones y críticas de las mujeres a la ciencia, UNAM, México.

Butler, Judith. (2009) "Performatividad, precariedad y políticas sexuales", en: Revista de Antropología Iberoamericana.321-336.

Calle Alzate, Laura y María del Carmen Villarreal Villamar (2017). "Etnografía dentro y fuera de los estudios migratorios: una revisión pertinente", en: Sociedade e Cultura, vol. 20, núm. 2, julio-diciembre, pp. 51-73 Universidade Federal de Goiás Goiania, Brasil

Castañeda Salgado, Martha Patricia (2006) "La antropología feminista hoy: algunos énfasis claves" en: Revista Mexicana de Ciencias Políticas y Sociales, vol. XLVIII, núm. 197, mayo-agosto, 2006, pp. 35- 47, Universidad Nacional Autónoma de México, Distrito Federal, México

Castañeda Salgado, Martha Patricia (2010) "Etnografía Feminista” en: Blazquez Graf, Norma, Fátima Flores Palacios y Maribel Ríos Everardo (Coords.) Investigación Feminista. Epistemología, Metodología y Representaciones Sociales. pp. 217-238

Castañeda Salgado, Martha Patricia (2019) "Etnógrafas Etnografiadas: de posicionamientos, dislocaciones y ubicaciones epistémicas" en: Disparidades 74(1): e002b. doi: https://doi.org/10.3989/dra.2019.01.002.02.

Durand, Jorge (2020) "Migrantes Desarraigados. Mesoamérica Laboratorio Migrante", en: Botega Tulia, Delia Dutra e Igor B. Cunha, Movilidad en la Frontera. Tijuana como espacio de (re) construcción de la vida, Centro Scalabriniano de Estudos Migratórios, Brasilia, pp. 19-70.

Düvell, Franck (2012) "Transit migration: A blurred and politicised concept", en: Population, Space, Place, 18. Wiley Online Library. pp. 415-427. 
Gell, Alfred (1992) The Anthropology of Time, Cultural Constructions of Temporal Maps and Images, Oxford, Berg.

Gregorio Gil, Carmen (2014) "Traspasando las fronteras dentro-fuera: Reflexiones desde una etnografía feminista", en: AIBR Revista de Antropología Iberoamericana, vol. 9. Número 3, septiembre-diciembre, pp. 297-322

Gregorio Gil, Carmen (2019) "Explorar posibilidades y potencialidades de una etnografía feminista", en: Disparidades 74(1): e002a. doi: https://doi.org/10.3989/dra.2019.01.002.01.

Haraway, Donna (1988) "Situated Knowledges: The Science Question in Feminism and the Privilege of Partial Perspective" en: Feminist Studies, vol. 14, núm. 3, 575-599.

Haraway, Donna (1991) "Conocimientos situados: La cuestión científica en el feminismo y el privilegio de la perspectiva parcial", en: Ciencia, cyborgs y mujeres: La Reivindicación de la naturaleza, Ediciones Cátedra y Universitat de Valencia e Instituto de la Mujer, Madrid, pp. 313-346.

Harding, Susana (2002) “¿Existe un método feminista?” En: Bartra, Eli (Coord.) Debates en torno a una metodología feminista (34), México, UNAM/UAMXochimilco, pp. 9-34.

Jeffrey, Bob y Geoff, Troman (2004) Time for ethnography. British Educational Research Journal, 30(4), 535-548.

Lamas, Marta (1986) "La Antropología feminista y la categoría de género", en: Nueva Antropología, vol. viii, núm. 30, pp. 173-198.

Luna Cuatlapantzi, Sergio (2019) “¡No es discriminación, es miedo! Desafíos para la asistencia humanitaria desde el albergue "La Sagrada Familia"', en: Diarios del Terruño. Reflexiones sobre Migración y Movilidad (8), p. 108-117.

Marcus, George (1995) Ethnography in /of the World System: The Emergence of MultiSited Ethnography. 
Marcus, George (1998) Ethnography through Thick and Thin, New Jersey: Princeton University. 79-104.

París Pombo, María Dolores (2016) "Políticas migratorias restrictivas y violencia institucional contra los migrantes", en: Ecuador Debate 97: 85-102.

Tinat, Karine (2017) "Introducción", en: Tinat, Karine y Alvarado, Arturo (coord.) Sociología y Género: Estudios en torno a performances, violencias y temporalidades, México: El Colegio de México.

Toledo González, Mónica Patricia (2014) Entre muchachas y señoras. Arreglos particulares en el trabajo doméstico remunerado en México, Tesis para obtener el grado de Doctora en Antropología, CIESAS, DF.

Sciortino, Silvana (2012). La etnografía en la construcción de una perspectiva de género situada. Clepsydra. Revista Internacional de Estudios Feministas y Teoría del Género (11), 41-58. En Memoria Académica. Disponible en: http://www.memoria.fahce.unlp.edu.ar/art_revistas/pr.11149/pr.11149.pdf

Sheller, Mimi y John Urry (2018) "Movilizando el nuevo paradigma de las movilidades", en: Revista del Área de Estudios Urbanos, UBA, pp. 333-355

Silva Ríos, Carlos y César Burgos Dávila (2011) "Tiempo Mínimo-conocimiento suficiente: La cuasi-etnografía sociotécnica en Psicología Social” en: Psicoperspectivas. Individuo y Sociedad, Vol 2, Pontifica Universidad Católica de Valparaíso, Chile

Vargas Cetina, Gabriela (2007) “Tiempo y Poder: La Antropología del Tiempo”, en: Revista Nueva Antropología, mayo, año/vol. XX, número 067 Universidad Nacional Autónoma de México, Distrito Federal, pp. 41-64

Videoconferencias FCPyS. (2020, 1 septiembre). Etnografía digital [Vídeo]. Yotube. https://www.youtube.com/watch?v=kB2UN3MCpHY

Zunino Singh, Dhan (2018) "Ciudades, prácticas y representaciones en movimiento. Notas para un análisis cultural de la movilidad como experiencia urbana", En: Tempo soc. [online] vol.30, n.2 pp.35-54. [en línea] http://www.scielo.br/scielo.php? script=sci_arttext\&pid=S0103$20702018000200035 \&$ lng $=$ en\&nrm=iso 